\title{
Reducing the Toxicity of Tetracycline Solutions and the Kinetics of Decomposition under the Action of DBD in Oxygen
}

\author{
A. Gushchin, ${ }^{a, *}$ V. Grinevich, ${ }^{a}$ E. Kvitkova, ${ }^{a}$ R. Chugunov, ${ }^{a}$ T. Izvekova, ${ }^{a}$ \\ N. Kruchinina, ${ }^{b}$ V. Emzhina, ${ }^{b}$ N. Ivantsova, ${ }^{b} \&$ V. Rybkin ${ }^{c}$

\begin{abstract}
aDepartment of Industrial Ecology, Ivanovo State University of Chemistry and Technology, Ivanovo, Russia; 'Department of Industrial Ecology, Russian State University of Chemical Technology, Moscow, Russia; 'Department of Microelectronic Devices and Materials, Ivanovo State University of Chemistry and Technology, Ivanovo, Russia

*Address all correspondence to: A. Gushchin, Department of Industrial Ecology, Ivanovo State University of Chemistry and Technology, Ivanovo, Russia, E-mail: a_guschin@bk.ru
\end{abstract}

\begin{abstract}
The effects of a dielectric barrier discharge (DBD) in oxygen on the kinetics of the decomposition and of product formation of aqueous solutions of tetracycline (THC) were studied. The kinetics of THC decomposition obeyed the first kinetic order, and the degree of decomposition reached $90 \%$. The rate constants and the energy efficiency of the decomposition process were determined. The decomposition products of THC were carboxylic acids, aldehydes, $\mathrm{CO}$, and $\mathrm{CO}_{2}$. The toxic effect of water was determined by the survival rate of freshwater crustaceans Daphnia magna Straus and fish Poecillia reticulata Peters. Treatment with DBD led to a significant reduction in the toxicity of the solutions (by $94.8 \%$ ).
\end{abstract}

KEY WORDS: tetracycline decomposition, oxygen DBD, solution toxicity, kinetics

\section{INTRODUCTION}

The current intensive production and use of drugs leads to their constant and unauthorized release into the environment, especially into bodies of water. Sources of such pollution are pharmaceutical companies, hospitals, pharmacies, livestock and poultry farms, where medicines are also used, and, finally, the consumer of medicines. Indeed, because antibiotics are poorly absorbed and are almost not susceptible to metabolic processes in humans and animals, approximately $40 \%-90 \%$ of consumed antibiotics are excreted in urine and feces in an unchanged form or as metabolites. ${ }^{1,2}$

Researchers find bioaccumulation of antibiotics in water samples from reservoirs, in sediments, and in aquatic plants and animals. ${ }^{3}$ Numerous publications in the field of water purification concern the study of technologies for removing persistent organic pollutants, particularly pharmaceuticals. The most technically promising and cost-effective methods for removing persistent organic impurities are oxidative processes,${ }^{4}$ such as the decomposition of pharmaceuticals under the action of a dielectric barrier discharge (DBD).$^{5-6}$ The rate and efficiency of the destruction of pharmaceutical products by promising oxidative methods (in particular, using DBD) depend on many factors, such as the structure of the drug, the initial concentration of the pollutant, as well as the electrical characteristics of the barrier discharge. In addition, the configuration of the discharge device itself also 
determines the mechanism and efficiency of decomposition of pollutants. ${ }^{7}$ DBD reactors show high efficiency in the decomposition of a wide class of organic pollutants present in water to the final oxidation products, such as $\mathrm{CO}_{2}$ and $\mathrm{H}_{2} \mathrm{O}$.

This report is a study of the processes of degradation of tetracycline in DBD in oxygen. Tetracycline was chosen because of its wide use, high environmental sustainability, and the lack of research on its plasma-chemical destruction.

\section{EXPERIMENTAL}

The object of the study was aqueous solutions of tetracycline hydrochloride (THC) (manufactured by Biosintez, Russia), with concentrations varying in the range of 0.02 to $0.1 \mathrm{~g} / 1$.

Processing THC water solutions was performed on the set up of the DBD with a coaxial-type reactor, the scheme of which is given by Grinevich et al. ${ }^{8}$ The reactor vessel was a Pyrex glass tube with an internal diameter of $22 \mathrm{~mm}$, which served as a dielectric discharge barrier. An external electrode $12 \mathrm{~cm}$ long was located on the surface of a glass tube. The internal electrode, with a diameter of $8 \mathrm{~mm}$ of aluminum alloy, was coated with a hydrophilic fiberglass cloth with a thickness of about $1 \mathrm{~mm}$. The treated solution flowed through glass fabric in film mode. The volumetric flow rate of the THC solution entering the reactor varied in the range of $0.15-0.5 \mathrm{ml} / \mathrm{sec}$. The countercurrent solution was supplied with technical oxygen (99.8\%). Gas flow rate was $3 \mathrm{~cm}^{3} / \mathrm{sec}$ under normal conditions. The flow rate of the solution was regulated by a peristaltic pump and determined the residence time of the solution in the discharge zone $\left(\tau_{\mathrm{R}}\right)$, which was calculated as follows:

$$
\tau_{\mathrm{R}}=\frac{\pi \times D \times h \times L}{Q}
$$

where $D$ is the diameter of the coating of fiberglass, $h$ is the film thickness of the solution, $L=12 \mathrm{~cm}$ is the length of the discharge zone, $Q$ is the solution flow rate.

The thickness of the liquid film was calculated by the equation for a smooth laminar flow from the ratio: ${ }^{9}$

$$
h=\left(\frac{3 v \times Q}{g \times \pi \times D}\right)^{1 / 3}
$$

where $v$ is the kinematic viscosity and $g$ is the acceleration of gravity.

The discharge was excited from a high-voltage transformer of industrial frequency $(50 \mathrm{~Hz})$. The voltage was monitored using a high-voltage probe, and the discharge current was determined by the voltage drop across a resistor $(100 \mathrm{Ohm})$ connected in series to the ground circuit. Both signals were simultaneously controlled by a digital twochannel oscilloscope GW Instek GDS-2072 (Taiwan). Root mean square (RMS) voltage varies in the range from $6 \mathrm{kV}$ to $13 \mathrm{kV}$. In this case, the RMS discharge current was 
$0.1-0.8 \mathrm{~mA}$. The power inputted in the discharge was determined by integrating the product of the current and the voltage waveforms over the period.

The content of tetracycline in the samples was controlled by a photometric method based on the formation of a colored complex of tetracycline in an alkaline solution, which has a yellow-green color. ${ }^{10}$ We also measured changes in the absorption spectra in the UV-visible region of the spectrum. A Hitachi U-2001 spectrophotometer (Japan) was used.

The total amount of carboxylic acids was determined by the photometric method by the color reaction of the carboxyl group with ammonium m-vanadate. Calibration was carried out on acetic acid. ${ }^{11}$

The total concentration of aldehydes was measured using fluorescent method (spectro-fluorimeter Fluorat-02, Russia). The fluorescent substance was formed as the interaction product of aldehyde and 1,3-cycloxehanedione in the presence of the ammonium ions. ${ }^{12}$ In the analysis, the wavelength of the exciting light was $395 \mathrm{~nm}$, and the wavelength for registration was $465 \mathrm{~nm}$. The maximum error in the determination of acids was $10 \%$, and the aldehyde $20 \%$.

The content of nitrate ions in the solution was determined by UV absorption at a wavelength of $210 \mathrm{~nm}$ (Kaplunenko et al. ${ }^{13}$ ).

The concentration of chloride ions was determined by the mercurometric method, after absorption of the gas mixture into water (two absorption vessels of $5 \mathrm{~cm}^{3}$ of water). The method is based on titration of chloride ions in an aqueous extract with mercury (II) nitrate solution in the presence of a diphenylcarbazone indicator. ${ }^{11}$

The concentrations of $\mathrm{CO}_{2}$ and $\mathrm{CO}$ in the gas phase were determined chromatographically. The chromatograph system for $\mathrm{CO}$ included a methanator (catalytic conversion of $\mathrm{CO}$ to $\mathrm{CH}_{4}$ ) and a flame ionization detector. A Chromatech 5000.2 (Chromatek, Russia) chromatograph was used. The chromatograph system was calibrated using $\mathrm{CO}_{2}$ and $\mathrm{CO}$ gases of chromatographic purity.

The toxic effect of water was determined by biotesting according to the survival rate of freshwater crustaceans Daphnia magna Straus ${ }^{14}$ and fish Poecillia reticulata Peters. ${ }^{15}$ The following criteria were used for toxic effects. 1 . Mean lethal time $\left(\mathrm{LT}_{50}\right)$ : The period during which $50 \%$ of individuals die in the analyzed sample. If the period is more than 96 hours, then there is no acute toxic effect of the test sample on test organisms. 2 . The average lethal rate of dilution of water $\left(\mathrm{LRD}_{50-48}\right)$, water extracts, causing the death of $50 \%$ of the test objects during the 48 -hour exposure. 3 . Harmless multiplicity of dilution of water $\left(\mathrm{HMD}_{10-48}\right)$, water extracts, causing the death of no more than $10 \%$ of the test objects for the 48-hour exposure.

\section{RESULTS AND DISCUSSION}

\section{A. Decomposition Kinetics}

With an increase in the initial concentration of tetracycline hydrochloride (THC) in the model solution by 15 times (from 0.042 to $0.655 \mathrm{mmol} / \mathrm{l}$ ), the degree of destruction 
decreased from $87 \%$ to $31 \%$ (Fig. 1). This may be due to both the lack of active particles involved in the oxidation process, and the residence time of the treated solution with the plasma zone. Therefore, further experiments were carried out in the range of initial concentrations of tetracycline from 0.042 to $0.218 \mathrm{mmol} / \mathrm{l}$, with effective decomposition of THC observed (more than 50\%).

Reducing the volume flow rate of the solution, and, consequently, increasing the residence time of the processed solution with the discharge zone, had a significant impact on the degree of destruction. In the working range of initial concentrations, THC decomposed quite effectively in $\mathrm{DBD}$. The maximum degree of destruction reached $75 \%-89 \%$ (Fig. 2).

The decomposition kinetics was well described by the equation of the first kinetic order (the lines in Fig. 2, $\mathrm{R}^{2} \geq 0.98$ ), which was obtained in the study (see Gushchin et al. ${ }^{16}$ ) of the plug flow reactor:

$$
n_{c}=n_{\text {in }} \times \exp \left(-k \times \tau_{\mathrm{R}}\right)
$$

where $k$ is the effective degradation rate constant, $n_{c}$ and $n_{i n}$ are concentrations at the inlet and outlet of the reactor.

Using these data, the rates, $W_{D}$, and energy yields, $\varphi$ (the number of decomposed molecules per $100 \mathrm{eV}$ of inputted energy) were calculated for the solution residence time $\tau_{\mathrm{R}}=k^{-1}$, as suggested by Bobkova and Tybkin. ${ }^{17}$ The following equations were used:

$$
\phi=\frac{Q \times n_{i n} \times 0.63 \times N_{A B} \times 1.6 \times 10^{-19} \times 100}{P}
$$

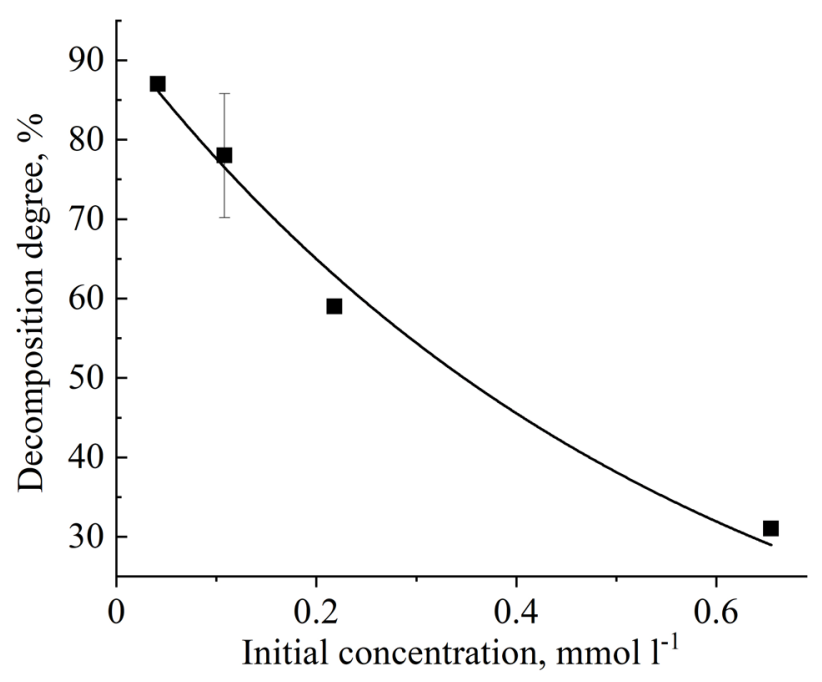

FIG. 1: The degree of decomposition as a function of initial concentration. The residence time is $2.8 \mathrm{~s}$. The discharge power is $7 \mathrm{~W}$. 

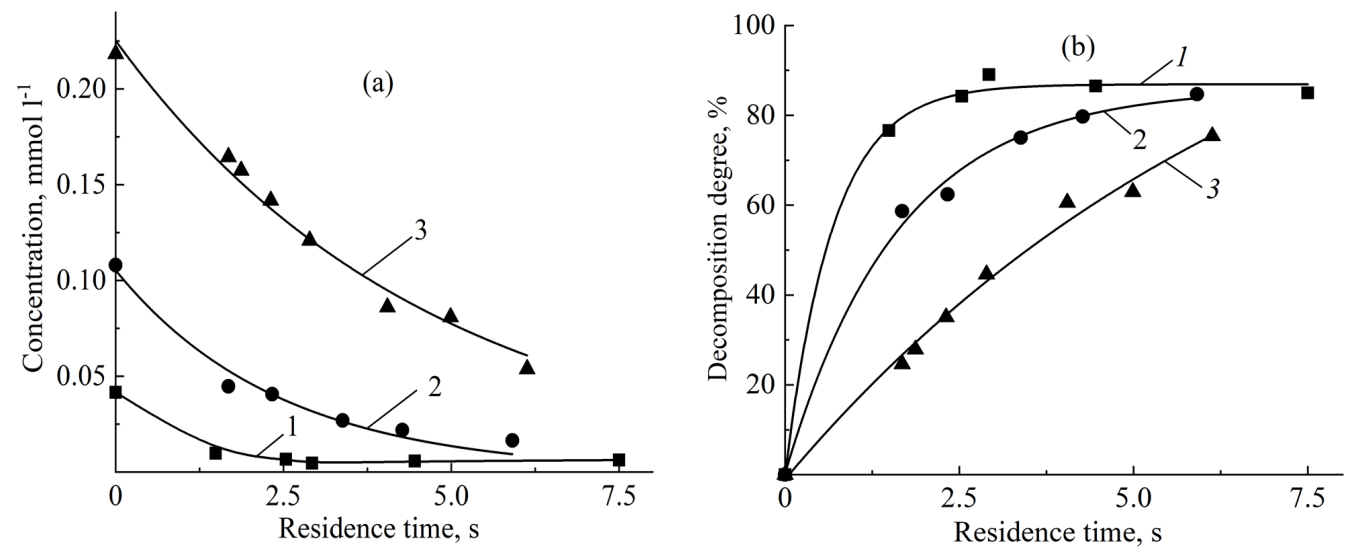

FIG. 2: Kinetics (a) and the degree of destruction (b) of tetracycline hydrochloride in the DBD at different residence times of solution with the discharge. $1-3-$ the TCH initial concentrations are $0.042,0.108$, and $0.218 \mathrm{mmol} / 1$, respectively. The discharge power is $7 \mathrm{~W}$.

$$
W_{D}=k \times n_{\text {in }} \times \exp (-1)
$$

where $Q$ is the solution flow rate $\left(1 \mathrm{~s}^{-1}\right)$ at the decomposition degree of $0.63, N_{A B}$ is the Avogadro number, $1.6 \times 10^{-19}$ is the charge of an electron, $P$ is the inputted power $(\mathrm{W})$, $n_{\text {in }}-\mathrm{mol} / 1$.

The effective rate constants, degradation rates, and energy yields of decomposition are presented in Table 1.

The given values of the energy yields are close to the results obtained when processing a solution of phenol $(0.01 \div 0.03 \text { molecules } / 100 \mathrm{eV})^{17}$ and about 3 times less in comparison with 2,4-dichlorophenol $(0.05 \div 0.17$ molecules $/ 100 \mathrm{eV})$ in the DBD in this concentration range. ${ }^{16}$ When treating an aqueous solution of diclofenac (a pharmaceutical preparation with the formula $\mathrm{C}_{14} \mathrm{H}_{11} \mathrm{Cl}_{2} \mathrm{NO}_{2}$ ) in a pulsed corona discharge with an initial concentration of $50 \mathrm{mg} / \mathrm{l}$, the rate of decomposition was $0.39 \mu \mathrm{mol}(1 \cdot \mathrm{s})^{-1}$ that is, almost 43 times less than in our case. ${ }^{18}$ The energy yield at $50 \%$ of the degree of

TABLE 1: Rates, effective rate constants, and energy yields for THC decomposition ${ }^{1}$

\begin{tabular}{|c|c|c|c|}
\hline $\begin{array}{c}\text { Initial concentration, } \\
\mathbf{m m o l ~ l}^{\mathbf{- 1}}\end{array}$ & $\begin{array}{c}\text { Effective } \\
\text { degradation rate } \\
\text { constant, } \mathbf{~}^{\mathbf{1}}\end{array}$ & $\begin{array}{c}\text { Decomposition rate, } \\
\boldsymbol{\mu m o l}(\mathbf{l} \times \mathbf{s})^{-\mathbf{1}}\end{array}$ & $\begin{array}{c}\text { Energy yield, } \\
\text { molecules per } \\
\mathbf{1 0 0} \mathbf{~ e V}\end{array}$ \\
\hline 0.042 & $0.81 \pm 0.06$ & 11.8 & 0.020 \\
\hline 0.108 & $0.41 \pm 0.03$ & 16.7 & 0.038 \\
\hline 0.218 & $0.21 \pm 0.02$ & 16.7 & 0.056 \\
\hline
\end{tabular}

${ }^{1}$ The discharge power is $7 \mathrm{~W}$. 
diclofenac decomposition was equal to $1 \mathrm{~g}(\mathrm{kWh})^{-1}$ and for tetracycline in DBD, it was $5 \mathrm{~g}(\mathrm{kWh})^{-1}$; that is, DBD with a flow-through system is more efficient than a pulsed corona discharge.

Carboxylic acids and aldehydes in the liquid phase, as well as $\mathrm{CO}$ and $\mathrm{CO}_{2}$ in the gas phase, were products of the destruction of THC. The concentration of aldehydes increased with increasing residence time of the solution with the discharge zone. The concentration of carboxylic acids passed through a maximum (Fig. 3). The concentrations of $\mathrm{CO}$ and $\mathrm{CO}_{2}$ molecules in the gas phase decreased with increasing solution contact time (Fig. 4). This type of kinetic curve shows that the carboxylic acids
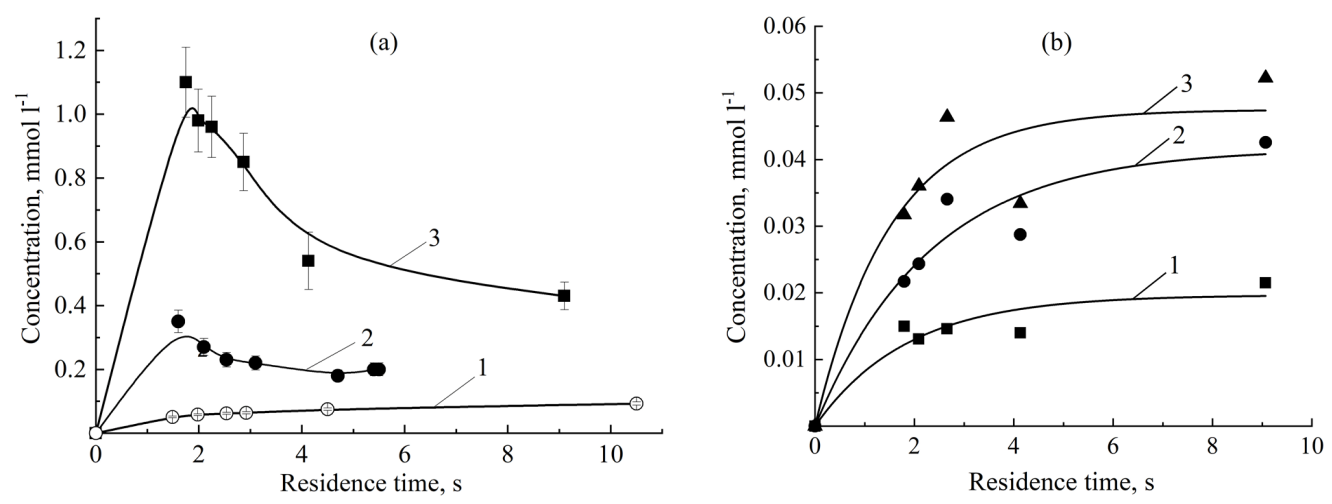

FIG. 3: The kinetics of the formation of carboxylic acids (a) in terms of acetic acid and aldehydes (b) during the decomposition of THC in DBD. 1,2,3 - the THC initial concentration is 0.042 0.108 , and $0.218 \mathrm{mmol} / 1$, respectively. The discharge power is $7 \mathrm{~W}$.
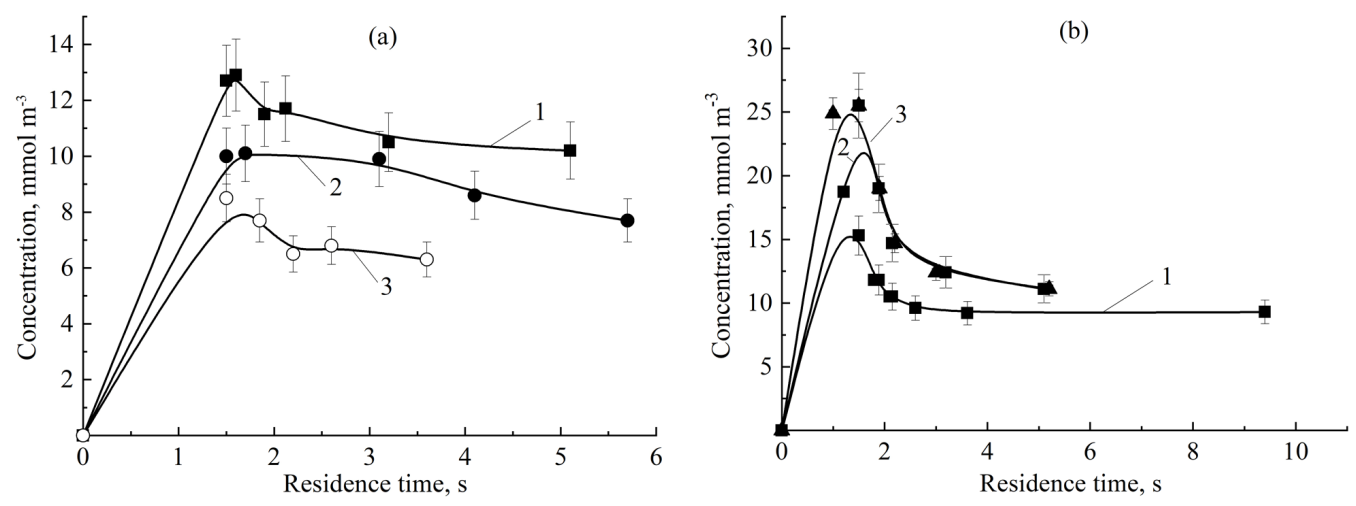

FIG. 4: Kinetics of the formation of $\mathrm{CO}_{2}$ (a) and $\mathrm{CO}$ (b) in the gas phase during the destruction of THC in the DBD. $1-3$ - the TCH initial concentration is $0.042,0.108$, and $0.218 \mathrm{mmol} / \mathrm{l}$, respectively. The discharge power is $7 \mathrm{~W}$. 
formed during the destruction of THC are intermediate products, the decomposition of which leads to the formation of carbon oxides and aldehydes. It should be noted that similar regularities (the sequence of formation of acids, aldehydes, and $\mathrm{CO}_{2}$ ) were observed during the decomposition of aqueous solutions of phenol, ${ }^{19}$ carboxylic acids, ${ }^{20,21}$ and 2,4-dichlorophenol. ${ }^{16}$ Apparently, these kinetics are common for derivatives of aromatic compounds.

The formation of carboxylic acids causes the solution to become acidic. The higher the concentration of the resulting acids, the lower the $\mathrm{pH}$ of the solution (Fig. 5).

Estimates indicate that the content of $\mathrm{CO}$ and $\mathrm{CO}_{2}$ in the measured degradation products is about $20 \%$ (i.e., the dominant decomposition products of THC are carboxylic acids, whose content in the products reaches $75 \%$ ). The carbon content in products is about $50 \%$ of its content in the original THC. Consequently, decomposition produces other carbon-containing products that were not measured. The solution subjected to the action of the discharge acquired a yellowish color, which is characteristic of nitro benzene derivatives. We were unable to measure the concentration of nitro derivatives due to the overlapping of their absorption spectrum and that of THC.

The dependence of the chloride ion concentration on the contact time is shown in Fig. 6. The independence of the concentration on the residence time, as well as its coincidence with the concentration of chloride ions in the untreated solution, indicates that these ions are not due to plasma action, but an electrolytic dissociation product. Since the concentration of THC decreases with increasing residence time, this means that part of the degradation products is composed of chlorine.

Nitrite and nitrate ions were absent in the treated solutions.

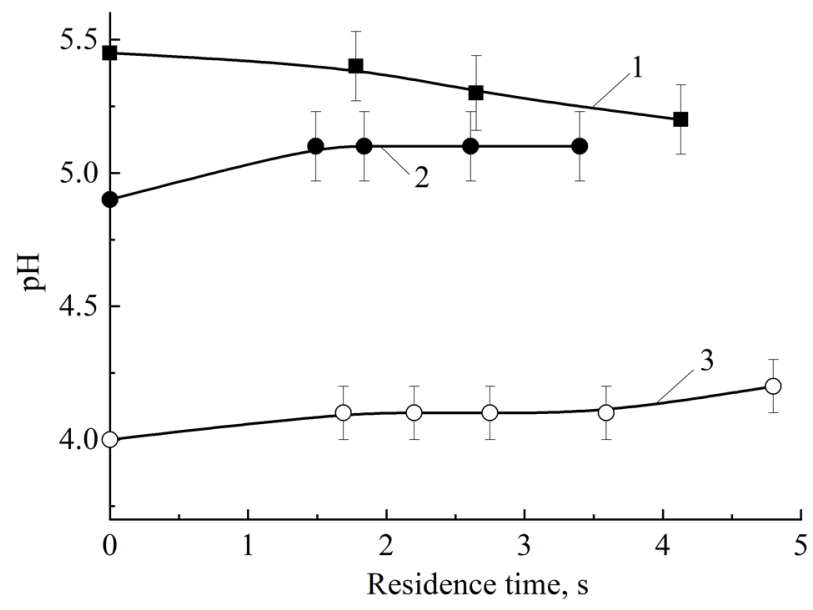

FIG. 5: The change in $\mathrm{pH}$ during the decomposition of THC in DBD. 1-3 THC initial concentrations are $0.042,0.108$, and $0.208 \mathrm{mmol} / 1$, respectively. The discharge power is $7 \mathrm{~W}$. 


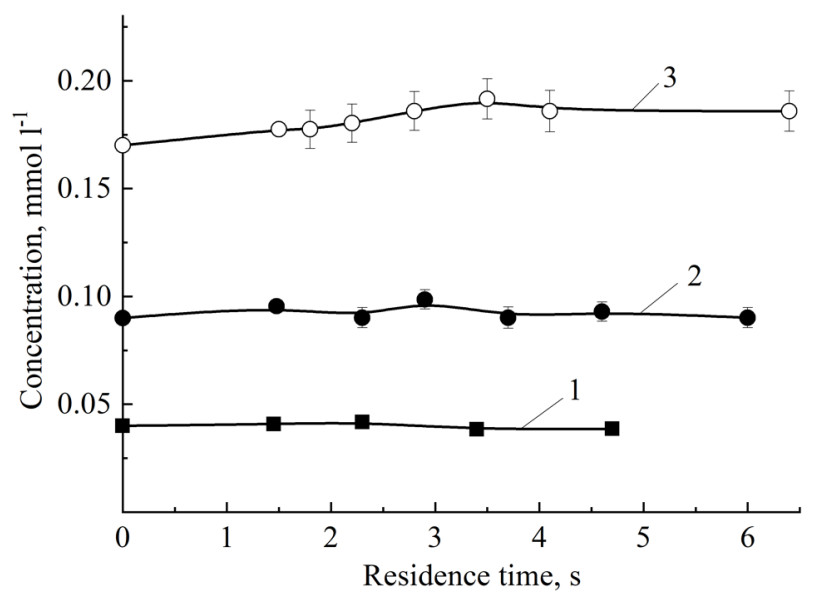

FIG. 6: The kinetics of the formation of chloride ions in solution during the destruction of THC in the DBD. $1-3-$ the TCH initial concentration is $0.042,0.108$, and $0.218 \mathrm{mmol} / \mathrm{l}$, respectively. The discharge power is $7 \mathrm{~W}$.

\section{B. Evaluation of Solution Toxicity}

The results of the evaluation of the toxicity of the investigated water samples before and after treatment by DBD are given in Table 2.

The biotest analysis of model solutions of tetracycline on Daphnia magna crustaceans showed that all solutions of tetracycline had an acute toxic effect on test

TABLE 2: Results of water toxicity before and after treatment in $\mathrm{DBD}^{1}$

\begin{tabular}{|c|c|c|c|c|c|c|}
\hline \multirow{2}{*}{$\begin{array}{c}\text { THC } \\
\text { concentration, g/l }\end{array}$} & \multicolumn{3}{|c|}{ Daphnia } & \multicolumn{3}{|c|}{ Guppy } \\
\hline & $\mathbf{L T}_{50}, \mathrm{~h}$ & LKD $_{50-48}$ & HMD $_{10-48}$ & $\mathbf{L T}_{50}, \mathrm{~h}$ & LKD $_{50-48}$ & HMD $_{10-48}$ \\
\hline \multirow[t]{4}{*}{0.02} & \multicolumn{6}{|c|}{ Before treatment } \\
\hline & 45 & 20.3 & 10 & 58 & 19.2 & 10 \\
\hline & \multicolumn{6}{|c|}{ After treatment } \\
\hline & 58 & 1.5 & 2 & 104 & 1.1 & 1 \\
\hline \multirow[t]{4}{*}{0.05} & \multicolumn{6}{|c|}{ Before treatment } \\
\hline & 40 & 25.9 & 15 & 57 & 24.9 & 15 \\
\hline & \multicolumn{6}{|c|}{ After treatment } \\
\hline & 64 & 4.2 & 5 & 81 & 3.1 & 2 \\
\hline \multirow[t]{4}{*}{0.1} & \multicolumn{6}{|c|}{ Before treatment } \\
\hline & 25 & 192.3 & 100 & 53 & 158.7 & 15 \\
\hline & \multicolumn{6}{|c|}{ After treatment } \\
\hline & 42 & 37.5 & 100 & 72 & 23.3 & 10 \\
\hline
\end{tabular}

${ }^{1}$ The discharge power is $7 \mathrm{~W}$. 
organisms, and chronic toxicity for fish Poecillia reticulata Peters (guppies). When the initial concentration of THC was increased by 50 times, the toxicity of the model solution increased by about 9.5 and 8.3 times for daphnia and guppy, respectively, and after treatment it decreased by 25.5 and 20.4 times. The results indicate a significant reduction in toxicity of solutions of THC processed in DBD compared with the initial model solutions.

\section{CONCLUSIONS}

DBD plasma is a promising tool for purifying water from tetracycline, and, possibly, from other antibiotics. Although decomposition produces some undesirable products (for example, aldehydes), in general, the effect of a discharge provides a significant reduction in the toxicity of the solution.

\section{ACKNOWLEDGMENTS}

This study was carried out in the frame of Project part of State Assignment of the Ministry of Education and Science of the RF, No 3.1371.2017/4.6 and it was supported by the RFBR Grant, Project No. 18-08-01239 A.

\section{REFERENCES}

1. Kumar K, Gupta SC, Chander Y, Singh AK. Antibiotic use in agriculture and its impact on the terrestrial environment. Adv Agron. 2005;87:1-54.

2. Barenboim GM, Chiganova MA. Pollution of surface water with drugs. Water: Chem Ecol. 2012;10:40-6.

3. Li W, Shi Y, Gao L, Liu J, Cai Y. Occurrence of antibiotics in water, sediments, aquatic plants, and animals from Baiyangdian Lake in North China. Chemosphere. 2012;89(11):1307-15.

4. Klavarioti M, Mantzavinos D, Kassinos D. Removal of residual pharmaceuticals from aqueous systems by advanced oxidation processes. Environ Int. 2009;35(2):402-17.

5. Krause H, Schweiger B, Prinz E, Kim J, Steinfeld U. Degradation of persistent pharmaceuticals in aqueous solutions by a positive dielectric barrier discharge treatment. J Electrostat. 2011;69(4):333-8.

6. Kim K-S, Kam S-K, Mok Y-S. Elucidation of the degradation pathways of sulfonamide antibiotics in a dielectric barrier discharge plasma system. Chem Eng J. 2015;271:31-42.

7. Mouele ESM, Tijani JO, Fatoba OO, Petrik LF. Degradation of organic pollutants and microorganisms from wastewater using different dielectric barrier discharge configurations - A critical review. Environ Sci Pollut Res. 2015;22(23):18345-62.

8. Grinevich VI, Kvitkova EY, Plastinina NA, Rybkin VV. Application of dielectric barrier discharge for waste water purification. Plasma Chem Plasma Process. 2011;31(4):573-83.

9. Bird RB, Stewart WE, Lightfoot EN. Transport phenomena. New York: John Wiley and Sons, Inc; 1960.

10. Solovey NV, Saavedra NF. Photometric determination of tetracycline hydrochloride. Pharmacy. 1974;23(4):72-3.

11. Lurie Y, Rybnikova AI. Chemical analysis of industrial wastewater. Moscow: Khimiya; 1974.

12. Russian National Standard GOST R 55227-2012. Water. Methods for determining the content of formaldehyde. 
13. Kaplunenko DD, Lobanov VB, Tishchenko PYA, Lazaryuk AYU, Zvalinsky VI. Measurement of nitrate content in the northwestern part of the Sea of Japan using a compact spectrophotometer. Underwater Studies Robotics. 2012;1(13):68-73.

14. Environmental regulation of the RF at the federal level. Toxicological methods of analysis. Methods for determining the toxicity of drinking, fresh natural and wastewater, water extracts from the soil,sewage sludge and waste of daphnia mortality (Daphnia magma Straus). Available from: https:// docplan.ru/Data2/1/4293772/4293772638.htm.

15. Guidelines for determining the method of biotesting toxicity of water, bottom sediments, pollutants and drilling fluids. Moscow; REFIA, NIA-Priroda; 2002. Available from: http://www.infosait.ru/ norma_doc/48/48872/index.htm.

16. Gushchin AA, Grinevich VI, Shulyk VYA, Kvitkova EYU, Rybkin VV. Destruction kinetics of 2,4 dichlorophenol aqueous solutions in an atmospheric pressure dielectric barrier discharge in oxygen. Plasma Chem Plasma Process. 2018;38(1):123-34.

17. Bobkova ES, Rybkin VV. Peculiarities of energy efficiency comparison of plasma chemical reactors for water purification from organic substances. Plasma Chem Plasma Process. 2015;35(1):133-42.

18. Dobrin D, Bradu C, Magureanu M, Mandache NB, Parvulescu VI. Degradation of diclofenac in water using a pulsed corona discharge. Chem Eng J. 2013;234:389-96.

19. Bobkova ES, Krasnov DD, Sungurova AV, Rybkin VV, Choi H-S. Phenol decomposition in water cathode of DC atmospheric pressure discharge in air. Korean J Chem Eng. 2016;33(5):1620-8.

20. Bobkova ES, Isakina AA, Grinevich VI, Rybkin VV. Decomposition of aqueous solution of acetic acid under the action of atmospheric-pressure dielectric barrier discharge in oxygen. Russian J Appl Chem. 2012;85(1):71-5.

21. Grinevich VI, Plastinina NA, Rybkin VV, Bubnov AG. Oxidative degradation of formic acid in aqueous solution upon dielectric-barrier discharge treatment. High Energy Chem. 2009;43(2):138-42. 